
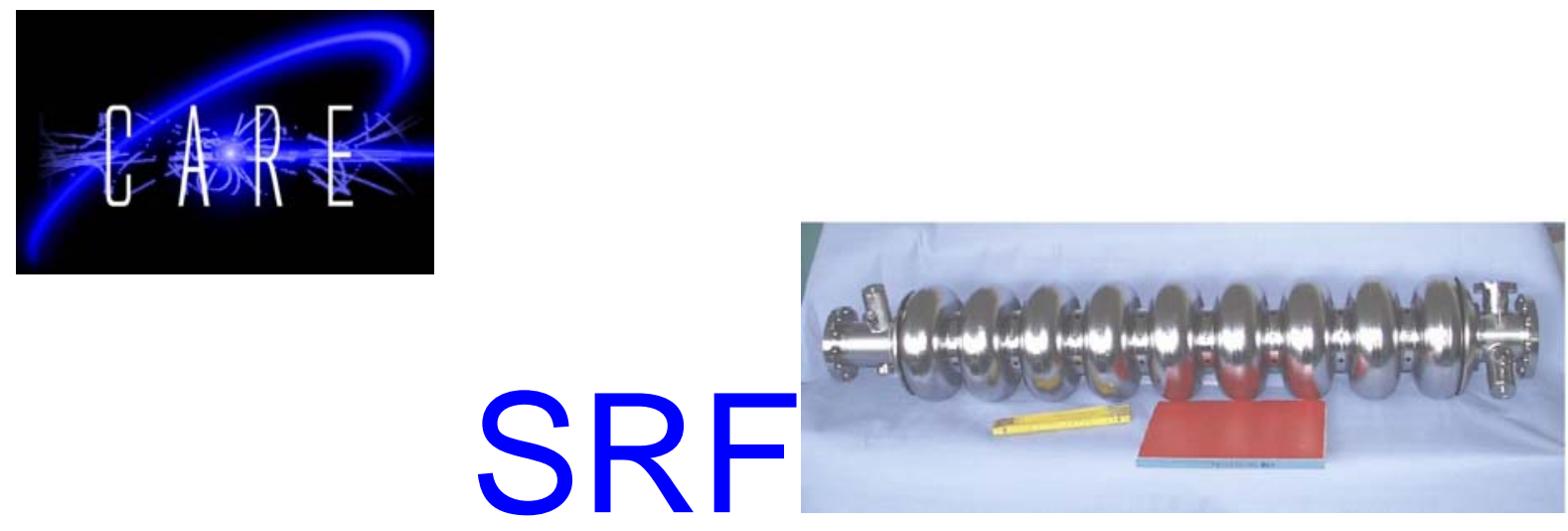

\title{
FULL CHARACTERIZATION AT LOW TEMPERATURE OF PIEZOELECTRIC ACTUATORS USED FOR SRF CAVITIES ACTIVE TUNING
}

\author{
M. Fouaidy, G. Martinet, N. Hammoudi, F. Chatelet, S. Blivet, A. Olivier, H. Saugnac \\ IPN Orsay, 91406 Orsay - France
}

\begin{abstract}
In the frame of the CARE project activities supported by EU, IPN Orsay participates to the development of a fast cold tuning system for SRF cavities operating at a temperature $\mathrm{T}=2 \mathrm{~K}$. The study is aimed at full characterization of piezoelectric actuators at low temperature. A new experimental facility was developed for testing various prototypes piezoelectric actuators and successfully operated for $\mathrm{T}$ in the range $1.8 \mathrm{~K}-300 \mathrm{~K}$. Different parameters were investigated as function of $\mathrm{T}$ : piezoelectric actuator displacement vs. applied voltage $\mathrm{V}$, capacitance vs. $\mathrm{T}$, dielectric and thermal properties vs. $\mathrm{T}$ and finally heating $\Delta \mathrm{T}$ due to dielectric losses vs. modulating voltage Vmod and frequency $\mathrm{f}$. We observed a decrease of the Full Range Displacement (FRD or $\Delta \mathrm{X}$ ) of the actuators from $40 \mu \mathrm{m} @ 300 \mathrm{~K}$ down to $1.8 \mu \mathrm{m}$ $3 \mu \mathrm{m} @ 1.8 \mathrm{~K}$, depending on both material and fabrication process of the piezostacks. Besides, both material and fabrication process have a strong influence on the shape of the characteristics $\Delta \mathrm{X}$ vs. $\mathrm{T}$ dependence. Moreover, the variations of loss tangent $(\operatorname{tg}(\delta))$ with $\mathrm{T}$ show a maximum at $\mathrm{T}$ in the range $30 \mathrm{~K}-120 \mathrm{~K}$. Finally a dedicated facility located at Orléans (CERI) for radiation hardness tests of actuators with fast neutrons at $\mathrm{T}=4.2 \mathrm{~K}$ was developed and the first beam tests results are summarized.
\end{abstract}

Contribution to the PAC05, Knoxville, USA

Work supported by the European Community-Research Infrastructure Activity under the FP6 "Structuring the European Research Area" programme (CARE, contract number RII3-CT2003-506395). 


\title{
FULL CHARACTERIZATION AT LOW TEMPERATURE OF PIEZOELECTRIC ACTUATORS USED FOR SRF CAVITIES ACTIVE TUNING
}

\author{
M. Fouaidy, G. Martinet, N. Hammoudi, F. Chatelet, S. Blivet, A. Olivier, H. Saugnac IPN Orsay, \\ 91406 Orsay - France
}

\begin{abstract}
In the frame of the CARE project activities supported by EU, IPN Orsay participates to the development of a fast cold tuning system for SRF cavities operating at a temperature $\mathrm{T}=2 \mathrm{~K}$. The study is aimed at full characterization of piezoelectric actuators at low temperature. A new experimental facility was developed for testing various prototypes piezoelectric actuators and successfully operated for $\mathrm{T}$ in the range $1.8 \mathrm{~K}-300 \mathrm{~K}$. Different parameters were investigated as function of $\mathrm{T}$ : piezoelectric actuator displacement vs. applied voltage V, capacitance vs. T, dielectric and thermal properties vs. T and finally heating $\Delta \mathrm{T}$ due to dielectric losses vs. modulating voltage $\mathrm{V}_{\text {mod }}$ and frequency $\mathrm{f}$. We observed a decrease of the Full Range Displacement (FRD or $\Delta \mathrm{X}$ ) of the actuators from $\sim 40 \mu \mathrm{m} @ 300 \mathrm{~K}$ down to $1.8 \mu \mathrm{m}-3 \mu \mathrm{m}$ (a) $1.8 \mathrm{~K}$, depending on both material and fabrication process of the piezostacks. Besides, both material and fabrication process have a strong influence on the shape of the characteristics $\Delta \mathrm{X}$ vs. T dependence. Moreover, the variations of loss tangent $(\operatorname{tg}(\delta))$ with $\mathrm{T}$ show a maximum at $\mathrm{T}$ in the range $30 \mathrm{~K}-120 \mathrm{~K}$. Finally a dedicated facility located at Orléans (CERI) for radiation hardness tests of actuators with fast neutrons at $\mathrm{T}=4.2 \mathrm{~K}$ was developed and the first beam tests results are summarized.
\end{abstract}

\section{INTRODUCTION}

Superconducting RF (SRF) cavities are very sensitive to small mechanical perturbations due to their narrow bandwidth $\Delta \mathrm{f}_{1 / 2}$. More precisely, high electromagnetic fields induce mechanical deformations $(\sim \mu \mathrm{m})$ of the cavity wall, leading to a frequency detuning $\Delta \mathrm{f} \approx \Delta \mathrm{f}_{1 / 2}$

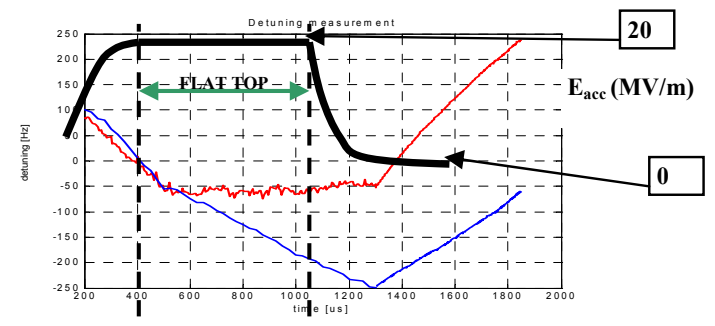

Figure 1: Compensation of Lorentz detuning by a piezoelectric actuator in a TESLA cavity for a flat top gradient $\mathrm{E}_{\mathrm{acc}}=20 \mathrm{MV} / \mathrm{m}$ (black curve): With compensation (red curve) $\Delta \mathrm{f} \sim-60 \mathrm{~Hz}$ during flat top. b) Without compensation (blue curve), $\Delta \mathrm{f} \sim-250 \mathrm{~Hz}$. of these accelerating structures (Fig.1). In order to reduce this effect, which results other ways in a substantial additional RF power so as to control $\mathrm{E}_{\mathrm{acc}}$, the SRF cavities are stiffened. However, the detuning factor $\mathrm{K}_{\mathrm{L}}$ reached with stiffened $\mathrm{SRF}$ cavities (e.g $\Delta \mathrm{f}=-\mathrm{K}_{\mathrm{L}} . \mathrm{E}_{\text {acc }}{ }^{2}, \mathrm{~K}_{\mathrm{L}} \approx 1-$ $\left.2 \mathrm{~Hz} /(\mathrm{MV} / \mathrm{m})^{2}\right)$ is still much higher than needed. An alternative strategy or dynamic compensation of Lorentz force detuning, using commercial piezoelectric actuators as active elements for deforming the resonator was successfully applied (Fig.1) to TESLA cavities [1]. At last, a piezo-tuning system is actually developed at IPN Orsay for high intensity proton linacs SRF cavities. In this paper, we will report the experimental results on the characterization of piezoelectric capacitive actuators at low temperature (i.e $1.8 \mathrm{~K}-300 \mathrm{~K}$ ), we obtained recently.

\section{EXPERIMENTAL SET UP AND TEST PROCEDURE}

A dedicated facility was designed and successfully used for this purpose: the experimental details, measurements method and the first results were presented previously [2]. The actuators tested, are PZT (Lead Zirconate Titanate) piezostacks from different companies. The 3D drawing of the test-cell (Fig. 2) fulfills the following main requirements:

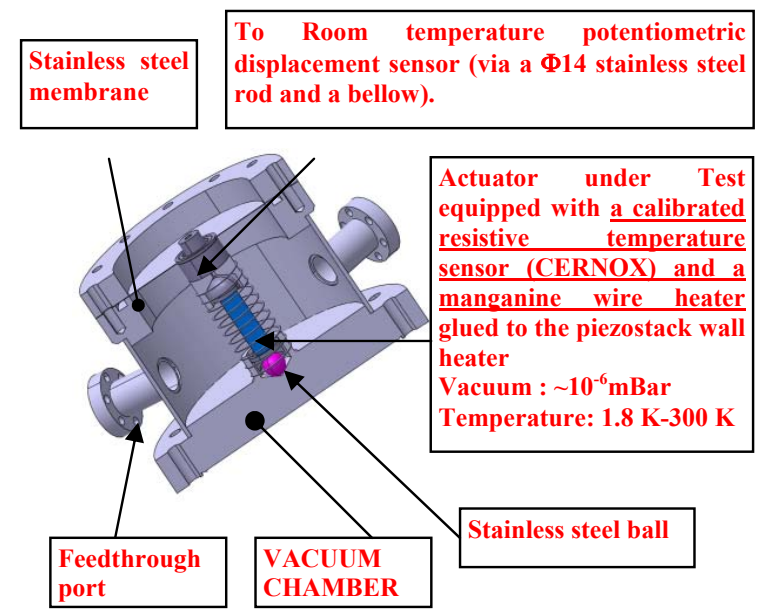

Figure 2: 3D drawing of the test-cell (See [2] for details).

-calibration and full characterization of piezoelectric actuator under vacuum and at controlled low temperature, -to avoid any shear forces, tilting and/or torsional forces which would damage the piezostacks actuator. 
The facility, which was upgraded as compared to the first version [2], operates in temperature range $1.8 \mathrm{~K}-$ $300 \mathrm{~K}$ and allows automatic measurements of the actuators properties. More precisely, we measured the following parameters at different temperatures $\mathrm{T}$ : a) displacement versus voltage characteristics, b) actuator capacitance $\mathrm{Cp}$ vs. $T, c)$ dielectric properties (dielectric constant: $\varepsilon_{\mathrm{r}}$, and loss tangent: $\operatorname{tg}(\delta)$, as function of $\mathrm{T}), \mathrm{d}$ ) heating $\Delta \mathrm{T}$ due to dielectric losses as function of the frequency $f$ and amplitude $\mathrm{V}_{\text {mod }}$ of the sinusoidal signal applied to the actuator, e) thermal properties (time constant: $\tau$, thermal resistance: $\mathrm{R}_{\mathrm{th}}$ and specific heat: $\mathrm{C}_{\mathrm{th}}$ ).

\section{RESULTS AND DISCUSSION}

Several low voltage actuators (Fig. 3) from different companies (JENA, NOLIAC, PICMA from PI) were tested.

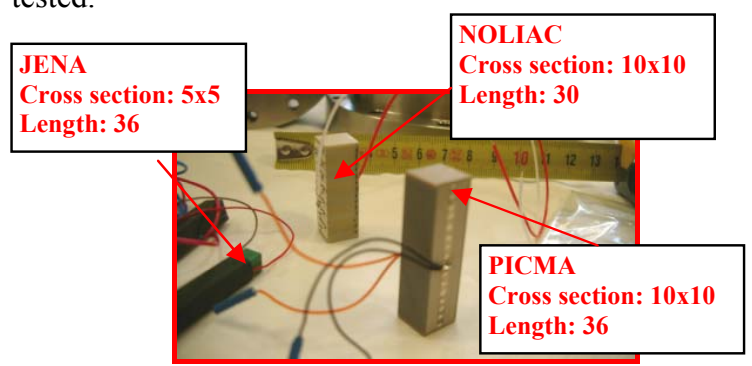

Figure 3: Piezoelectric actuators (Dimensions in $\mathrm{mm}$ ).

\section{Piezosystem JENA actuators results}

Actuators of different production series from piezosystem JENA were investigated [2]. These actuators, which are of the same type (FRD $\approx 42 \mu \mathrm{m} @ \mathrm{~T}=300 \mathrm{~K}$ (calibration curve given by JENA)), were rejected because of five main drawbacks and limitations:

1) Maximum stroke less than $2 \mu \mathrm{m}$ at $2 \mathrm{~K}(3 \mu \mathrm{m}$ are required),

2) Insufficient blocking force : 1 kN @ 300K $(3 \mathrm{kN}$ are required),

3) Low mechanical stiffness: $25 \mathrm{~N} / \mu \mathrm{m}(100 \mathrm{~N} / \mu \mathrm{m}$ are required),

4) Lack of fabrication reproducibility from batch to batch (i.e. different behaviour of FRD vs. T),

5) Very short lifetime when operated at $2 \mathrm{~K}$ (electrical breakdown and/or mechanical damages).

The experimental data previously reported (JENA \#9221[2]) show that the FRD of the actuator decreases strongly with T from $42 \mu \mathrm{m} @ 300 \mathrm{~K}$ down to $2 \mu \mathrm{m} @$ $2 \mathrm{~K}$. For this actuators, the measured variations of $\operatorname{tg}(\delta)$ at $100 \mathrm{~Hz}$ as function of $\mathrm{T}$ show a peak around $\mathrm{T} \sim 10 \mathrm{~K}-20 \mathrm{~K}$. As a consequence, when the actuator is subjected to a sine voltage, the dielectric losses $\mathrm{P}_{\text {diel }}$ versus $\mathrm{T}$ curve shows also a broad maximum around $\mathrm{T} \sim 10 \mathrm{~K}-20 \mathrm{~K}$. For a sinusoidal displacement of $1 \mu \mathrm{m}$ amplitude at a frequency of $100 \mathrm{~Hz}$, the thermal load to $1.8 \mathrm{~K}$ is lower than $1 \mathrm{~mW}$.

PICMA actuators results
These prototypes actuators from PI are not calibrated. We used JENA actuators and the displacement sensor for the calibration of PICMA (Fig. 5) and NOLIAC actuators. These data show the well known hysteresis @ 300K with a FRD of $40 \mu \mathrm{m} @ \mathrm{~V}_{\max }=120 \mathrm{~V}$. Note that this hysteresis is completely negligible for $\mathrm{T}<4.2 \mathrm{~K}$.

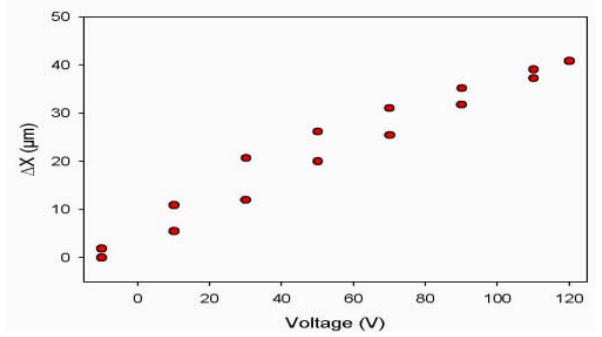

Figure 5: Calibration of actuator PICMA\#1@300 K.

The variations of the maximum actuator PICMA\#1 expansion $\Delta \mathrm{X}$ with temperature are shown in Fig. 6.

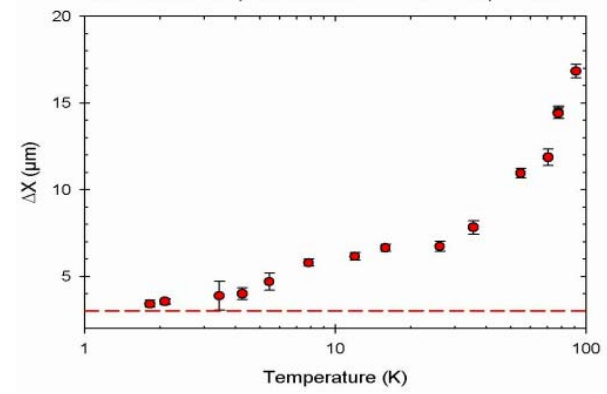

Figure 6: Variations of the full range $\left(\mathrm{V}_{\max }=120 \mathrm{~V}\right)$ displacement with temperature (Actuator: PICMA\#1).

These data show a strong decrease of the slope of $\Delta X$ vs. T curve with temperature. This behavior seems to be mainly due to the strong dependence (Fig. 7) of the actuator PICMA\#1 parallel capacitance $\mathrm{Cp}$ on $\mathrm{T}$. Note that FRD is decreased by a factor of $\sim 13$ when $T$ decreases from $300 \mathrm{~K}$ down to $2 \mathrm{~K}$ and this result is in the range of values reported previously by other authors [3].

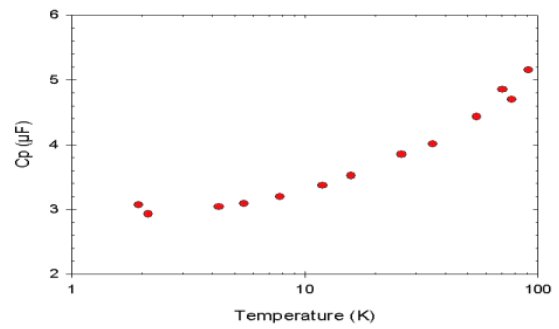

Fig. 7: Actuator capacitance versus temperature.

Moreover, at low temperature (i.e $\mathrm{T} \leq 100 \mathrm{~K}$ ), we notice (Fig. 8) a simple relationship between $\Delta \mathrm{X}$ and $\mathrm{C}_{\mathrm{p}}$ (i.e; $\Delta \mathrm{X} \propto \mathrm{C}_{\mathrm{p}}$ ). This behavior gives a straight-forward mean to calibrate actuators. Indeed, capacitance measurements are more simple and less time consuming, as compared to a true calibration (i.e. $\Delta \mathrm{X}$ vs. T) and specially for a large number of actuators (e.g. 1000 for the XFEL). 


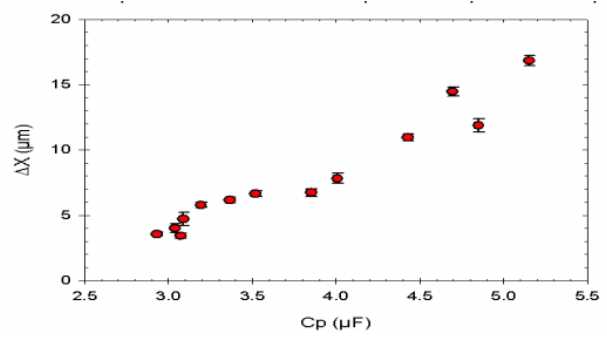

Figure 8: Full range displacement versus capacitance.

\section{Dielectric and thermal properties}

Measurements of the following parameters were performed for $\mathrm{T}$ ranging from $1.8 \mathrm{~K}$ to $300 \mathrm{~K}$ : a) dielectric properties (i.e. $\mathrm{Cp}, \operatorname{tg}(\delta) @ 100 \mathrm{~Hz}, 120 \mathrm{~Hz}$ and $1 \mathrm{kHz}$ ), heating $\Delta \mathrm{T}$ vs. sinusoidal voltage amplitude $\mathrm{V}_{\text {mod }}$ and frequency $f, b)$ thermal properties $\left(C_{t h}, R_{t h}\right.$ and $\left.\tau\right)$.

The dielectric constant $\varepsilon_{\mathrm{r}}$ of the material vs. T, which is deduced from $\mathrm{Cp}$, is obviously homothetic to the curve of Fig.7: $\varepsilon_{\mathrm{r}}$ decreases from $1454 @ 300 \mathrm{~K}$ to $328 @ 1.8 \mathrm{~K}$. The heating $\Delta \mathrm{T}$ versus time when the actuator is subjected to a sinusoidal voltage $(\mathrm{T}=1.8 \mathrm{~K})$ is shown in Fig. 9.

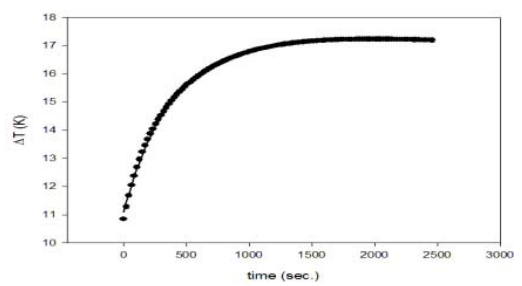

Fig. 9: Dielectric heating $\Delta \mathrm{T}$ of the actuator @ $\mathrm{T}=1.8 \mathrm{~K}$ (sinusoidal voltage : $\mathrm{V}_{\text {mod }}=1.5 \mathrm{~V}, \mathrm{f}=100 \mathrm{~Hz}$ ).

These data clearly show an exponential dependence on the time $\mathrm{t}: \Delta \mathrm{T}=\Delta \mathrm{T}_{\max } \cdot(1-\exp (-\mathrm{t} / \tau))$, where the time constant $\tau$ is simply given by $\tau=\mathrm{R}_{\mathrm{th}} \mathrm{C}_{\mathrm{th}}$. The fit to the data leads to the following values: $\tau=376 \mathrm{~s}, \mathrm{R}_{\mathrm{th}}=9.10^{5} \mathrm{mK} / \mathrm{mW}$ and $\mathrm{C}_{\mathrm{th}}=4.310^{-4} \mathrm{~J} / \mathrm{K}$. Note that $\mathrm{V}_{\text {mod }}$ corresponds to a displacement of $170 \mathrm{~nm}$ of the cavity wall (i.e. $\Delta \mathrm{f}=68 \mathrm{~Hz}$ ) with total dielectric losses $\mathrm{P}_{\text {diel }}=20 \mu \mathrm{W}$ and heating $\Delta \mathrm{T}=17 \mathrm{~K}$ (steady state value: see Fig. 9). Moreover, the heating $\Delta \mathrm{T}$ vs. modulation voltage amplitude and frequency is shown in 3D plot (Fig. 10). The observed heating (i.e. $\Delta \mathrm{T}=\mathrm{R}_{\mathrm{th}} . \mathrm{P}_{\text {diel }}$ ) is well described by the wellknown expression of the total dielectric losses $\mathrm{P}_{\text {diel }}$ (i.e. $\left.\Delta \mathrm{T} \propto \mathrm{P}_{\text {diel }}=\pi . f . C p . \mathrm{V}_{\text {mod }}^{2} \cdot \sin (\delta)\right)$. Note that the small departure from the quadratic dependence (1), observed at high modulation voltage amplitude and or frequency, is attributed to nonlinear effect resulting from $\mathrm{Cp}$ and $\sin (\delta)$ dependence on $\mathrm{T}$.

\section{CONCLUSION AND OUTLOOK}

A dedicated apparatus was developed for full characterization of piezoelectric actuators at low temperature $1.8 \mathrm{~K}-300 \mathrm{~K}$. Several PZT actuators from three different companies were fully characterized: $\Delta \mathrm{X}$

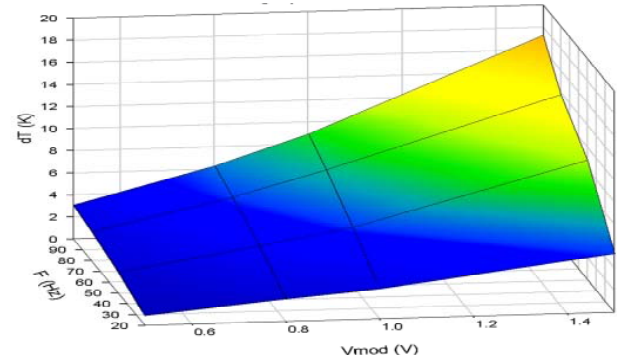

Figure 10: 3D plot o vs. heating modulation voltage amplitude and frequency.

$\Delta \mathrm{X}$ decreases strongly with $\mathrm{T}$ from $\sim 40 \mu \mathrm{m} @ \mathrm{~T}=300 \mathrm{~K}$ down to $1.8 \mu \mathrm{m}-3 \mu \mathrm{m} @ \mathrm{~T}=1.8 \mathrm{~K}$. The shape of $\Delta \mathrm{X}$ vs. T curve depends on the actuator material and fabrication process. For actuators of PICMA and NOLIAC type, $\Delta \mathrm{X}=2.8 \mu \mathrm{m}-3 \mu \mathrm{m} @ 1.8 \mathrm{~K}$ leading to a theoretical detuning compensation $\Delta \mathrm{f} \approx 1 \mathrm{kHz}$ for TESLA nine cells cavities. The dielectric losses of JENA actuators, for a sinusoidal (@f $\mathrm{f}=100 \mathrm{~Hz}$ ) displacement of $1 \mu \mathrm{m}$ amplitude at $1.8 \mathrm{~K}$, are lower than $1 \mathrm{~mW}$. Furthermore, four PICMA and four NOLIAC actuators were subjected to irradiation tests (CERI institute) at $\mathrm{T}=4.2 \mathrm{~K}$ with a fast neutrons beam (Energy spectrum: $1-15 \mathrm{MeV}$ ). A total dose of $\sim 2.10^{15} \mathrm{n} / \mathrm{cm}^{2}$ was achieved in 16 hours: neither damage nor anomalous behavior or performance degradation of these actuators were observed. Only $C_{p}$ increase, which are probably due to a thermal effect (i.e. heating with neutrons) were observed. A detailed report on irradiation will be published when data analysis is completed. A new apparatus for investigating the dynamic properties of actuators, effect of preloading on their characteristics is under development. Finally, the actuators will be integrated in a cold tuning system for TESLA cavities and tests will be performed soon in the horizontal cryostat facilities CRYHOLAB at Saclay and CHECHIA at Desy.

\section{ACKNOWLEDGEMENT}

We acknowledge the support of the European Community-Research Infrastructure Activity under the FP6 "Structuring the European Research Area" program (CARE, contract number-CT-20036506395). Many thanks to the CERI colleagues J. Briaud, L. Lepolotec, F. Durand, J.P Trasbot and machine team, and to the other colleagues from IPN Orsay (i.e. Accelerators Division and Radioprotection Group) for their valuable help.

\section{REFERENCES}

[1] M. Liepe et al., "Dynamic Lorentz Force Compensation with a Fast Piezoelectric Tuner', PAC 2001, Chicago, USA, June 2001, 1074-1076.

[2] M. Fouaidy et al. "Characterization of piezoelectric actuators for SRF cavities active tuning at low temperature', $11^{\text {th }}$ SRF Workshop, Germany, Nov. 2003.

[3] M. Locatelli et al., Rev. Sci. Instrum., Vol. 59,(1988), p. 661 . 